\title{
IV. Alntizen.
}

\section{Ẽrflärung.}

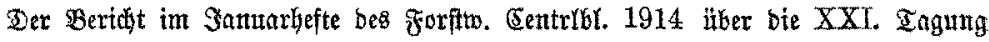

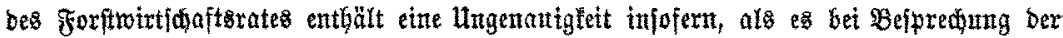

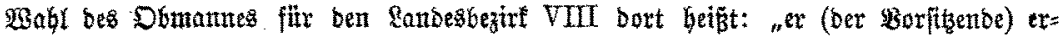
wähant.... mb befragt fobann ben Bertreter bes Bereins ber böberen Forfterenten

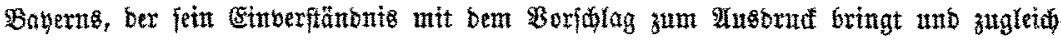
bittet Den $9 e r e i n$ thrnftig vorber befragen gal wollen".

Da id fitr bie zunäbif Beteiltgten aufflärenben Bertut in ben Mitteilungen bes

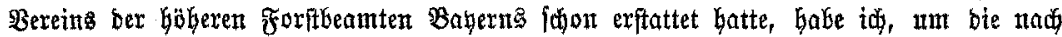

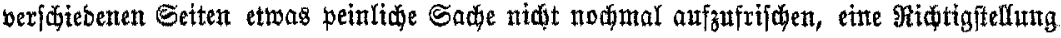
unterlafient.

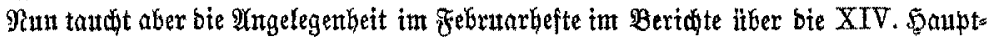

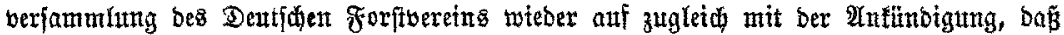
fie now in irgenb eitner form bejprodien werben jolle.

Daburd Gin to seranlabt, zut ertlären:

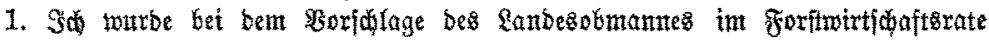

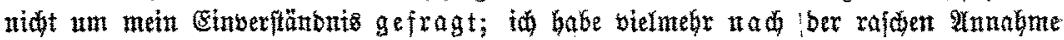

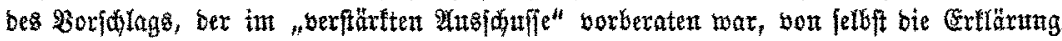

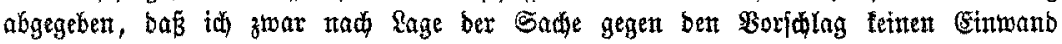
erheber wolle, baß id aber bitten mïffe, es mödite in Zutfunft ber von mix vertretene Berein ebenfo wor Ger gehört werbent wite anbere Bereine.

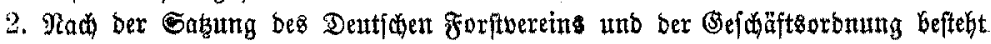

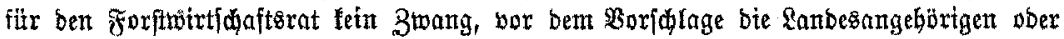

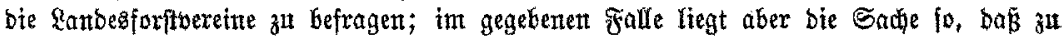

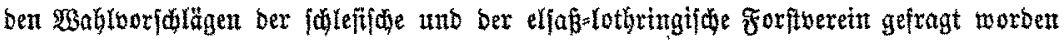
finb, ber Berein ber böheren Forftbenmten Baberns aber nidgt.

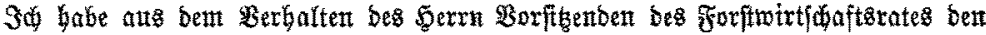

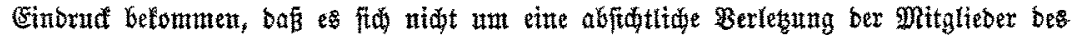

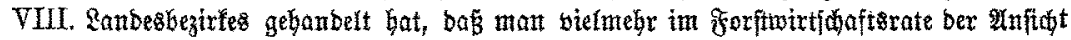

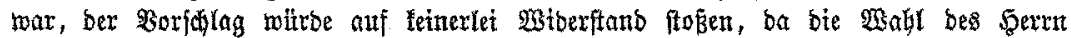
Dr. Mammen insbejonbere bon einent berrn aus Bayern betrieben worben wax. Das hat mir ein Mitglieb bes "verftärften Mrsfduluffę" befiätigt.

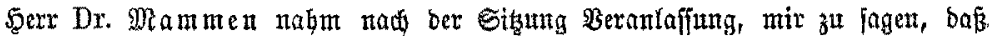

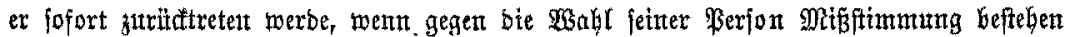

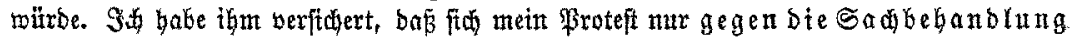
geriditet habe.

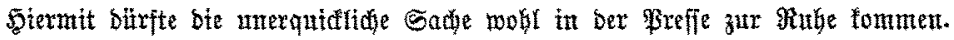

शf Blum,

\section{Jur Samenproventenzfrage.}

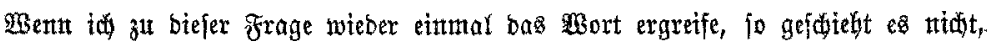

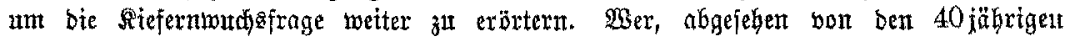
Beobaditutigen in ben baltifden Provinzen, atd nad ben neueften meftenropäifaen

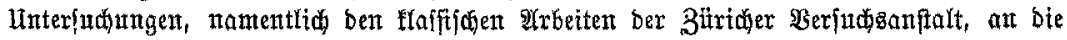

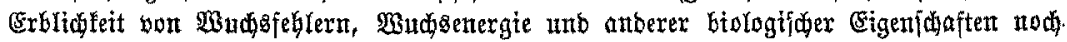

